\title{
MÔ PHỎNG TRAO ĐỔI NHIẸTT CỦA QUÁ TRÌNH BAY HƠI GIÁN TIẾP ÚNG DỤNG TRÖNG ĐIỀU HÒA KHÔNG KHÍ
}

\author{
LÊ VĂN HIÊN \\ Khoa Công nghệ Nhiệt lạnh, Truờng Đại học Công nghiệp thành phố Hồ Chí Minh; \\ hl.levanhien@googlemail.com
}

Tóm tắt. Điều hòa không khí tạo nên môi trường làm việc thoải mái, dễ chịu, góp phần làm tăng năng suất lao động, đặc biệt trong những ngày nóng bức. Phần lớn các hệ thống điều hòa hiện nay sử dụng chu trình máy nén cơ học dưới sự dẫn động của động cơ điện. Điều đó dẫn đến làm tăng phụ tải điện trong những tháng mùa hè, khi nhu cầu điều hòa tăng cao, có thể gây mất an toàn cho hệ thống điện. Làm mát không khí bằng phun ẩm là công nghệ thân thiện với môi trường, tiêu hao ít năng lượng và không sử dụng môi chất lạnh. Công nghệ này là giải pháp hữu hiệu có thể thay thế hệ thống điều hòa không khí thông dụng hiện nay hoặc thay thế một phần bằng cách làm mát không khí sơ bộ rồi cấp không khí đó cho hệ thống điều hòa không khí thông thường. Như vậy điều hòa không khí có thể thay thế từng phần hoặc thay thế toàn bộ bằng biện pháp phun ẩm. Trong bài này sẽ mô tả sơ đồ nguyên lý hoạt động của mô hình làm giảm nhiệt độ không khí bằng phun ẩm và thiết lập phương trình truyền nhiệt, truyền khối cho mô hình đó.

Từ khóa. mô phỏng, điều hòa không khí, trao đổi nhiệt, làm mát bằng không khí bay hơi, quá trình làm mát bay hơi, làm mát bay hơi gián tiếp

\section{SIMULATION ON HEAT EXCHANGER FOR INDIRECT EVAPORATIVE PROCESS APPLIES IN AIRCONDITIONING}

\begin{abstract}
Air conditioning systems are responsible for increasing men's work efficiency as well for his comfort, mainly in the warm periods of the year. Currently, the most used system is the mechanical vapor compression system. Furthermore, the higher electricity demand for cooling causes summer peaks, which may lead to high electricity prices and grid connected problems as black-outs. However, in many cases, evaporative cooling system can be an alternative to replace the conventional system, under several conditions, or as a pre-cooler in the conventional systems. The remaining cooling demand must be covered with alternative, environmentally friendly cooling technologies. This paper presents the basic principles of the evaporative cooling process for human thermal comfort, the principles of operation for the evaporative cooling system and the mathematical development of the equations of thermal exchanges, allowing the determination of the effectiveness of saturation to determinate the convective heat transfer coefficient with the mathematical calculation.
\end{abstract}

Keyword. simulation, air conditioning, heat changer, air evaporative cooling, evaporative cooling process, indirect evaporative cooling

\section{Các ký hiệu}

$d e_{h} \quad$ đường kính tương đương, $\mathrm{m}$

$\sigma \quad$ hệ số ẩm ướt

$\alpha \quad$ hệ số tỏa nhiệt đối lưu, $\mathrm{W} /\left(\mathrm{m}^{2} \mathrm{~K}\right)$

$\alpha_{d} \quad$ hệ số truyền khối, $\mathrm{kg} /\left(\mathrm{m}^{2} \mathrm{~s}\right)$

$\lambda \quad$ hệ số dẫn nhiệt, $\mathrm{W} /(\mathrm{mK})$

$m$ lưu lượng khối lượng, $\mathrm{kg} / \mathrm{s}$

$t, T \quad$ nhiệt độ $,{ }^{0} C, K$

$N \quad$ số lượng vách ngăn hoặc kênh

$\varphi \quad$ độ ẩm tương đối, $\%$

$\varepsilon_{w b}$ hiệu quả nhiệt độ bầu ướt

$K$ hệ số truyền nhiệt, $\mathrm{W} /\left(\mathrm{m}^{2} \mathrm{~K}\right)$

$\mathrm{L}_{\mathrm{x}}, \mathrm{L}_{\mathrm{y}}$ chiều dài và cao của thiết bị, $\mathrm{m}$

Le tiêu chuẩn Lewis

$\mathrm{Nu}$ tiêu chuẩn Nusselt

Re tiêu chuẩn Reynold 
Sc tiêu chuẩn Schmidt

$V \quad$ lưu lượng thể tích, $\mathrm{m}^{3} / \mathrm{s}$

$Q \quad$ dòng nhiệt, $\mathrm{W}$

$\mathrm{v}$ vận tốc, $\mathrm{m} / \mathrm{s}$

$\mu \quad$ hệ số nhớt động lực học, $\mathrm{kg} /(\mathrm{ms})$

\section{Các chỉ số}

$a$ dòng thứ cấp

$d_{p} \quad$ điểm đọng sương

$i$ đầu vào

$o$ đầu ra

$p \quad$ dòng sơ cấp

$v$ hơi $c_{p} \quad$ nhiệt dung riêng đẳng áp, $\mathrm{kJ} /(\mathrm{kgK})$

$i \quad$ enthalpy, $\mathrm{kJ} / \mathrm{kg}$

$W \quad$ màng nước

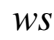

w

$s$

V

w

$w b$ mặt tiếp xúc nước và dòng thứ cấp

ở dạng lỏng

trạng thái bão hòa

ở dạng hơi

màng ẩm

bầu ướt

\section{GIỚI THIẸU}

Làm mát không khí bằng phun ẩm là quá trình truyền nhiệt, truyền khối trên cơ sở chuyển hóa lẫn nhau giữa nhiệt ẩn và nhiệt hiện giữa hơi nước và không khí. Phun ẩm có thể ở hai dạng: phun ẩm trực tiếp (direct evaporative cooling - DEC) và phun ẩm gián tiếp (indirect evaporative cooling - IEC).

Phun ẩm trực tiếp - DEC là công nghệ làm mát không khí có kết cấu đơn giản, tiết kiệm năng lượng, thân thiện với môi trường. Khi không khí lưu động qua những hạt nước nhỏ ly ty tạo thành màn sương do phun ẩm, hạt sương bay hơi vào không khí, không khí bị mất đi một lượng nhiệt để cấp cho ẩm bay hơi làm cho nhiệt độ không khí giảm xuống. Như vậy quá trình truyền nhiệt và truyền khối giữa không khí và ẩm được tiến hành ở nhiệt độ thấp hơn nhiệt độ môi trường, vì vậy nhiệt độ không khí giảm xuống đồng thời độ ẩm của không khí tăng lên. Đây là quá trình bay hơi đoạn nhiệt với enthalpy không khí không thay đổi. Quá trình này kết thúc khi không khí đạt tới trạng thái bão hòa.

Trong vùng khí hậu nóng ẩm thì DEC kém hiệu quả vì độ ẩm của không khí ngoài trời đã tương đối cao, rất gần đến trạng thái bão hòa. Để tăng khả năng cho ẩm bay hơi vào không khí gần bão hòa thì cần giảm độ ẩm của nó rồi phun ẩm, đó là phun ẩm gián tiếp (IEC).

Phun ẩm gián tiếp được thực hiện trong hai kênh dẫn đặt kề nhau, cách ly qua vách ngăn. Dòng không khí bên ngoài (gọi là dòng sơ cấp) lưu động vào kênh chứa chất hút ẩm (còn gọi là kênh khô), độ ẩm của dòng sơ cấp này bị hấp phụ bởi chất hút ẩm nên độ ẩm không khí ra khỏi kênh này giảm xuống. Kênh còn lại được phun ẩm ở dạng sương mù (còn gọi là kênh ướt). Dòng không khí từ phòng làm việc (gọi là dòng thứ cấp) sẽ lưu động qua kênh ướt. Như vậy IED, ngoài nhiệm vụ tách ẩm còn có vai trò như một thiết bị trao đổi nhiệt. Nhiệt lượng của dòng sơ cấp truyền cho dòng thứ cấp là trao đổi nhiệt đối lưu qua vách ngăn. Dòng thứ cấp có nhiệt độ thấp hơn nhiệt độ của dòng sơ cấp lại qua kênh ướt nên nhiệt độ của nó lại tiếp tục giảm xuống, làm gia tăng chênh lệch nhiệt độ của 2 dòng do vậy nhiệt lượng trao đổi giữa hai kênh cũng được tăng cường. Quá trình trao đổi nhiệt này cũng làm cho nhiệt độ chất hút ẩm giảm xuống, góp phần làm tăng khả năng hấp phụ hơi nước của chất hút ẩm. Với cấu tạo như trên thì trong giai đoạn phun ẩm gián tiếp không những làm giảm nhiệt độ không khí sơ cấp mà còn làm tăng hiệu quả hoạt động của quá trình. Hình 1 dưới đây mô tả phần phun ầm gián tiếp.

Nhiệt độ và độ ẩm của dòng sơ cấp ra khỏi kênh hâp phụ ẩm đã giảm xuống. Dòng này được dẫn vào phun ẩm trực tiếp. Qua DEC này, nhiệt độ không khí lại tiếp tục giảm.

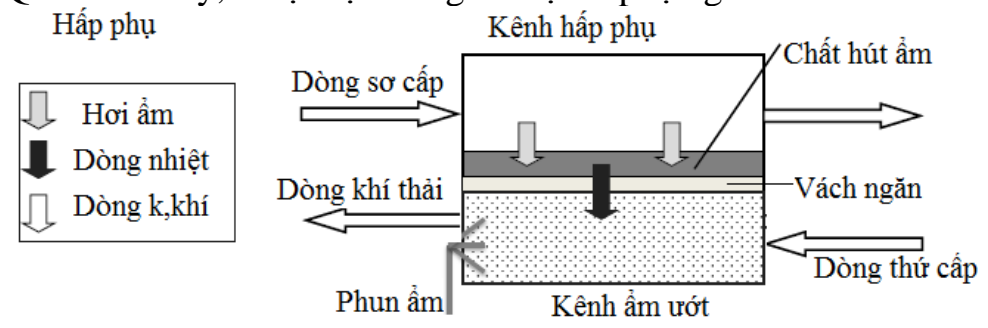

Hình 1. Không khí được tách ẩm ở giai đoạn phun ẩm gián tiếp

Có thể điều chỉnh lưu lượng của dòng sơ cấp, cách sắp xếp chất hút ẩm để có thể điều chỉnh nhiệt độ của dòng này trước khi dòng lưu động vào $\mathrm{DEC}$. Độ ẩm và nhiệt độ của không khí đưa vào phòng làm 
việc sẽ điều chỉnh qua phần phun ẩm gián tiếp. Như vậy có thể điều chỉnh nhiệt độ và độ ẩm và của không khí đi vào phòng làm việc khi dòng thứ cấp ưu thông qua IEC rồi tiếp tục qua DEC. Hình 2 minh họa sơ đồ kết cấu của thiết bị điều hòa không khí. Trên hình vẽ, bánh xe truyền nhiệt và bánh xe hút ẩm hiện diện cho IEC. Không khí bên ngoài khi lưu động qua bánh xe hút ẩm và bánh xe truyền nhiệt, dòng sơ cấp giảm độ ẩm và nhiệt độ rồi qua phun ẩm để nhiệt độ lại tiếp tục giảm xuống. Quá trình này hoàn thành một chu kỳ, gọi là chu kỳ hấp phụ, nó thực hiện chức năng điều hòa không khí.

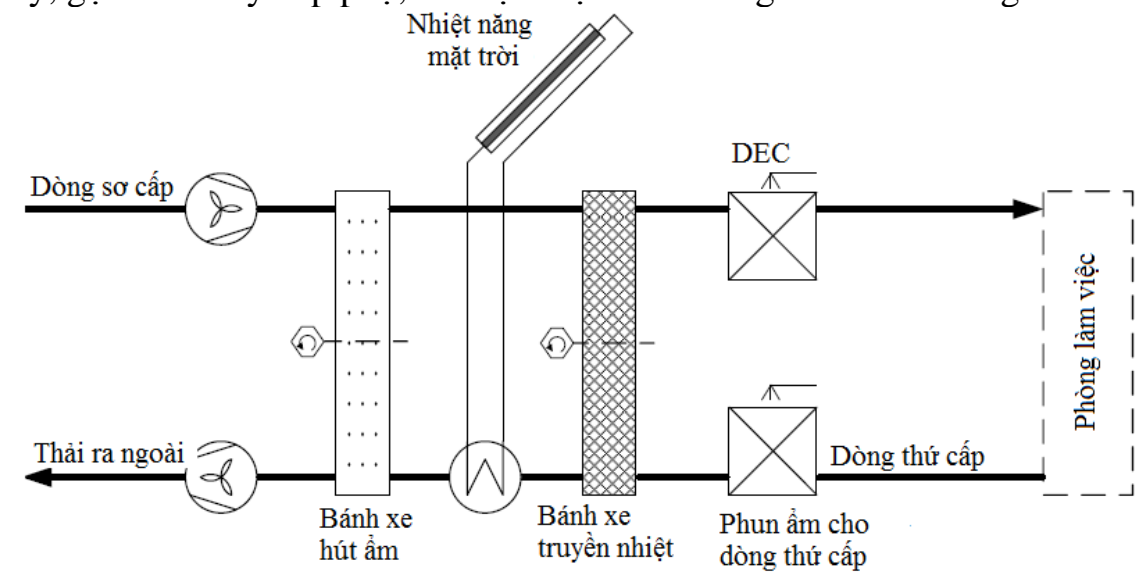

Hình 2. Sơ đồ kết cấu thiết bị điều hòa không khí bằng phun ẩm

Khi chất hút ẩm đã bão hòa, không còn khả năng hấp phụ ẩm của không khí nữa thì phải giải phóng ẩm ra khỏi chất hút ẩm. Để ẩm thóat ra khỏi chất hút ẩm thì cần cung cấp nhiệt năng cho chất hút ẩm đã bão hòa. Nhiệt độ của nguồn nhiệt này không cao nên có thể được cấp từ nhiệt thải trong sản xuất công nghiệp hoặc năng lượng tái tạo (trên hình vẽ là bức xạ mặt trời). Khi đó dòng thứ cấp, bắt nguồn từ phòng làm việc lưu động vào bộ thu năng lượng mặt trời. Dòng thứ cấp được hâm nóng, nhiệt độ của dòng được gia tăng rồi lưu động qua chất hút ẩm đã bão hòa để giải phóng ẩm cho nó. Như vậy quá trình này thực hiện chu kỳ giải phóng ẩm. Hình 4 mô tả quá trình giải phóng ẩm từ chất hút ẩm đã bão hòa.

Như vậy quá trình điều hòa không khí phải thực hiện với hai chu kỳ rời rạc. Để quá trình liên tục thì cần phải có hai thiết bị hoạt động đồng thời, kết nối phù hợp để hỗ trợ cho nhau. Khi thiết bị này hoạt động theo chu kỳ hấp phụ thì thiết bị kia hoạt động theo chu kỳ giải phóng ẩm. Bánh xe hút ẩm và bánh xe truyền nhiệt quay với vận tốc phù hợp để đặt chất hút ẩm chưa bão hòa vào vị trí, tại đó dòng sơ cấp lưu động qua và chất hút ẩm đã bão hòa vào vị trí có không khí nóng thổi qua.

Quá trình giảm nhiệt độ và độ ẩm không khí được mô tả trên biểu đồ hình 3 dưới đây. Như vậy khả năng giảm nhiệt độ không khí phụ thuộc vào mức độ giảm độ ẩm của dòng sơ cấp và lượng nhiệt trao đổi giữa dòng sơ cấp và dòng thứ cấp. Vì vậy cần lựa chọn chất hút ẩm phù hợp với nhu cầu điều hòa không khí. Mặt khác, để tăng cường truyền nhiệt cần phải kết hợp giữa chênh lệch nhiệt độ và bề mặt trao đổi nhiệt để lượng nhiệt trao đổi giữa hai dòng (sơ cấp và thứ cấp) là lớn nhất. 


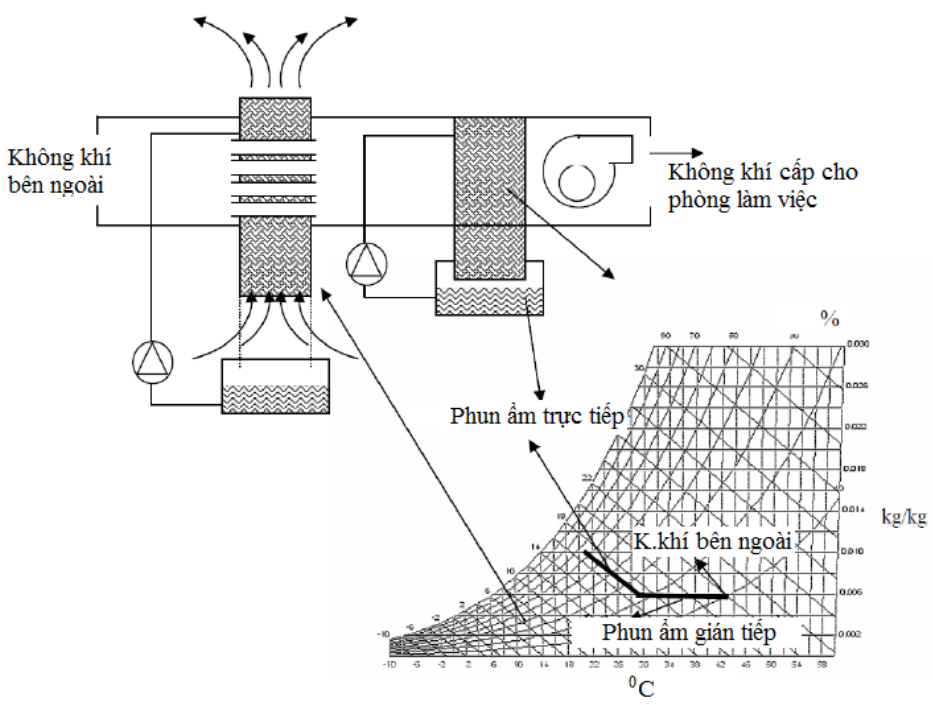

Hình 3. Biểu đồ biểu thị quá trình thay đổi trạng thái của không khí qua phun ẩm

Quá trình truyền nhiệt và truyền khối trong IEC đặc trưng tổng thể cho hệ thống nên chúng tôi chỉ thiết lập quá trình tính toán cho phần này.

\section{THIẾT LẬP PHƯƠNG TRÌNH TÍNH TOÁN CHO IEC}

Các phương trình bảo toàn khối lượng và năng lượng được thiết lập cho vy phân một thể tích nằm trên bề mặt vách ngăn trong kênh hấp phụ của IEC với điều kiện trao đổi nhiệt ổn định. Mồ hình tính toán sẽ được thiết lập dựa trên kết cấu của IEC. Các phương trình sẽ mô tả toàn diện quá trình truyền nhiệt và truyền khối khi ẩm bay hơi từ màn phun sương ẩm ướt vào không khí và trao đổi nhiệt giữa dòng sơ cấp và thứ cấp. Sơ đồ lưu động các dòng để thiết lập phương trình tính toán được minh họa ở hình 4 , trong đó không khí bên ngoài là dòng sơ cấp được dẫn vào kênh hấp phụ, dòng thứ cấp bắt đầu từ phòng làm việc chuyển động qua phun ẩm rồi dẫn qua kênh giải phóng ẩm. Dòng sơ cấp và thứ cấp lưu động ngược chiều và dòng ẩm của màn phun sương chuyển động cắt ngang cả hai dòng sơ cấp và thứ cấp. Sơ đồ lưu động của các dòng và các thông số của nó được thể hiện trên hình 4.

Trước khi thiết lập phương trình, chúng tôi đề xuất một vài giả thiết có thể phù hợp với điều kiện thực tế như sau: Hệ thống được cách nhiệt hoàn hảo, nhiệt lượng không truyền ra môi trường xung quanh; Nhiệt và ẩm được truyền theo hướng pháp tuyến, không khuyếch tán theo hướng chuyển động của dòng không khí; Vách ngăn kín, không cho hơi ẩm xuyên qua;Bỏ qua bức xạ giữa dòng thứ cấp và dòng phun ẩm;Quá trình ổn định, tính chất nhiệt vật lý và lưu lượng của dòng không thay đổi trong suốt quá trình.;Nhiệt dung riêng của 3 dòng là hằng số;Nhiệt độ bề mặt tiếp xúc giữa không khí và ẩm (hạt nước) ở màn sương phun ẩm thì bằng nhiệt độ nước, không khí trên bề mặt đó ở trạng thái bão hòa.
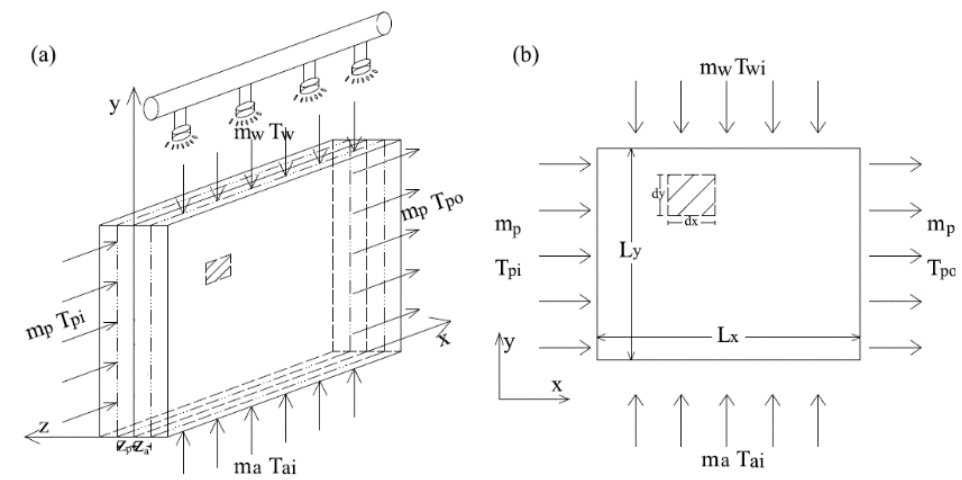

Hình 4 - Sơ đồ lưu động của các dòng trong tọa độ 3 chiều (a) và 2 chiều (b) 


\section{MÔ PHỎNG TRAO ĐỔI NHIÊTT CỦA QUÁ TRÌNH BAY HƠI GIÁN TIÊP ÚNG DỤNG TRONG ĐIÊU HÒA KHÔNG KHÍ}

Miền tính toán được lựa chọn là một nửa kích thước của kênh sơ cấp và thứ cấp như trên hình 4(a), hai kênh này đối xứng. Để thể hiện rõ quá trình hoạt động của thiết bị, miền tính toán được chia thành nhiều thể tích kiểm soát với diện tích bề mặt vô cùng bé $\mathrm{dx}$.dy như được thể hiện trong hình 5 . Như vậy lượng ẩm dịch chuyển qua miền tính toán sẽ là:

Lượng ẩm dịch chuyển theo miền tính toán trong dòng sơ cấp sẽ là:

$$
m_{p}=\rho v_{p} L_{y} \cdot \frac{1}{2} z_{p}
$$

theo miền tính toán trong dòng thứ cấp:

$$
m_{a}=\rho v_{a} L_{x} \cdot \frac{1}{2} z_{a}
$$

và theo miền tính toán của dòng phun sương:

$$
m_{w}=\rho L_{x} \Gamma
$$

Như vậy lưu lượng cho dòng sơ cấp, thứ cấp và ẩm của dòng phun sương tương ứng có các giá trị là $m_{p} \frac{d y}{L_{y}}, m_{a} \frac{d x}{L_{x}}, m_{w} \frac{d x}{L_{x}}$. Trên hình 6 biểu diễn các thông số của các dòng lưu động trên $1 / 2$ kênh của dòng sơ cấp (sau này gọi là kênh khô) và trên $1 / 2$ dòng thứ cấp (sau này gọi là kênh ướt).

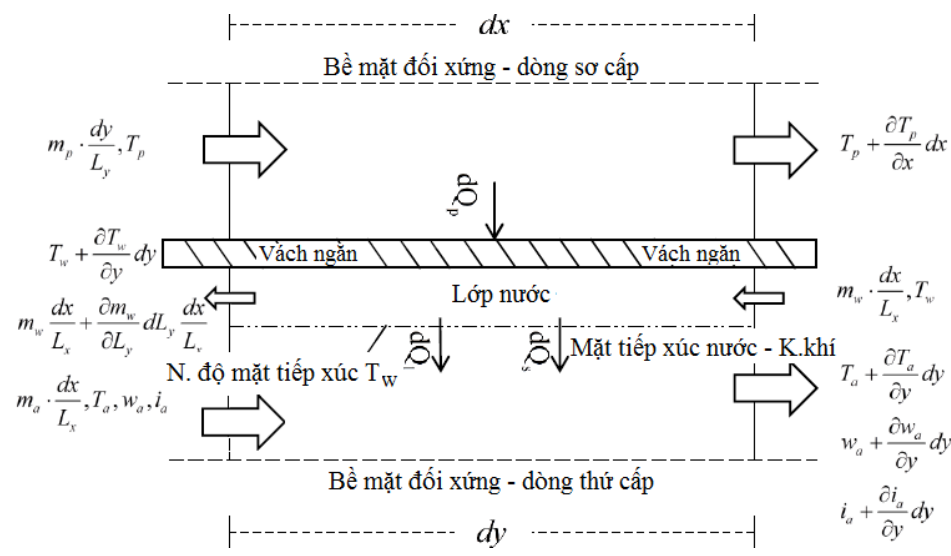

Hình 5. Phân bố các dòng trên một nửa phần tử đang khảo sát

\subsection{Dòng sơ cấp}

Dòng sơ cấp từ bên ngoài lưu động vào kênh hấp phụ (kênh khô), truyền cho bề mặt phân cách lượng nhiệt $\mathrm{dQ}_{\mathrm{p}}$ và lượng nhiệt này lại truyền bằng đối lưu cho màn sương tạo nên do phun âm ở kênh ướt. Tuy nhiên trong thực tế thì lớp ẩm này sẽ không bao phủ toàn bộ bề mặt vách ngăn. Như vậy qua diện tích của vách ngăn, trao đổi nhiệt sẽ tiến hành với 2 cặp lưu chất: một là truyền từ dòng sơ cấp (không khí) đến ẩm của màn sương qua phần diện tích ướt, hai là qua phần diện tích còn lại thì nhiệt lượng truyền từ dòng sơ cấp qua vách ngăn đến không khí của dòng thứ cấp. Như vậy, cần phải xác định

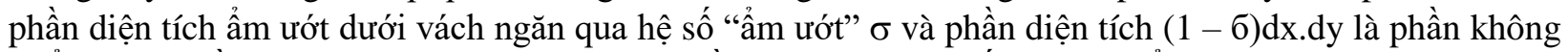
bị ẩm ướt. Phần lớn nhiệt lượng từ $\mathrm{dQ}_{\mathrm{p}}$ sẽ truyền cho dòng thứ cấp qua lớp ẩm. Nhiệt hiện của dòng sơ cấp truyền cho lớp ẩm sẽ là:

$$
d Q_{p w}=K_{w}\left(T_{p}-T_{w}\right) \sigma \cdot d x \cdot d y
$$

Và nhiệt hiện của dòng sơ cấp truyền cho dòng thứ cấp qua phần diện tích khô sẽ là:

$$
d Q_{p a}=K_{a}\left(T_{p}-T_{a}\right)(1-\sigma) d x . d y
$$

Như vậy tổng nhiệt lượng dòng sơ cấp truyền cho dòng thứ cấp sẽ là:

$$
d Q_{p}=d Q_{p w}+d Q_{p a}=K_{w}\left(T_{p}-T_{w}\right) \sigma \cdot d x \cdot d y+K_{a}\left(T_{p}-T_{a}\right)(1-\sigma) d x . d y
$$

Phương trình cân bằng nhiệt của dòng sơ cấp như sau: 


$$
d Q_{p}=-m_{p} \frac{d y}{L_{y}} c_{p}\left(T_{p}+\frac{\partial T_{p}}{\partial x} d x-T_{p}\right)
$$

Dấu trừ trong phương trình trên biểu thị hướng dòng nhiệt ra khỏi dòng sơ cấp.

Kết hợp phương trình (6) và (7) thì phương trình sau được thiết lập:

$$
-m_{p} \frac{c_{p}}{L_{y}} \cdot \frac{\partial T_{p}}{\partial x}=K_{w}\left(T_{p}-T_{w}\right) \sigma+K_{a}\left(T_{p}-T_{a}\right)(1-\sigma)
$$

Sau biến đổi sẽ dẫn đến phương trình sau:

$$
\frac{\partial T_{p}}{\partial x}=\frac{L_{y}}{m_{p} c_{p}}\left[K_{w}\left(T_{w}-T_{p}\right) \sigma+K_{a}\left(T_{a}-T_{p}\right)(1-\sigma)\right]
$$

Trong các phương trình trên $\mathrm{K}_{\mathrm{w}}$ là hệ số truyền nhiệt của dòng nhiệt từ dòng sơ cấp đến lớp ẩm, $\mathrm{K}$ là hệ số truyền nhiệt giữa không khí dòng sơ cấp và dòng thứ cấp. Các hệ số truyền nhiệt đó được biểu thị bằng biểu thức sau:

$$
\begin{aligned}
& \frac{1}{K_{w}}=\frac{1}{\alpha_{p}}+\frac{\delta_{v n}}{\lambda_{v n}}+\frac{1}{\alpha_{w}} \\
& \frac{1}{K_{a}}=\frac{1}{\alpha_{p}}+\frac{\delta_{v n}}{\lambda_{v n}}+\frac{1}{\alpha_{a}}
\end{aligned}
$$

Trong hai biểu thức trên đã bỏ qua nhiệt trở tiếp xúc và $\delta_{\mathrm{vn}}$ là bề dày vách ngăn, $\lambda_{\mathrm{vn}}$ là hệ số dẫn nhiệt của vách ngăn.

\subsection{Lớp ẩm của màn phun sương}

Lớp ẩm của màn phun sương trong kênh ướt không những hấp thu nhiệt từ dòng sơ cấp mà còn thực hiện biến đổi nhiệt ẩn thành nhiệt hiện trong dòng thứ cấp. Về lý thuyết thì tồn tại một màng ẩm rất mỏng ở bề mặt tiếp xúc giữa ẩm và không khí, nhiệt độ bề mặt này chính bằng nhiệt độ màng ẩm, không khí ở bề măt đó đã bão hòa [8]. Trao đổi nhiệt hiện $d Q_{\mathrm{s}}$ phụ thuộc vào chênh lệch nhiệt độ của ẩm $\mathrm{T}_{\mathrm{w}}$ và nhiệt độ $\mathrm{T}_{\mathrm{a}}$ của dòng thứ cấp. Mặt khác sự biến đổi nhiệt ẩn $d Q_{l}$, liên quan đến sự bay hơi nước vào dòng thứ cấp. Quá trình đó phụ thuộc vào chênh lệch nhiệt độ của bề mặt tiếp xúc giữa ẩm với không khí và nhiệt độ không khí ở dòng thứ cấp. Các dòng nhiệt đó sẽ là:

$$
\begin{aligned}
& d Q_{s}=\alpha_{a}\left(T_{w}-T_{a}\right) \sigma . d x . d y \\
& d Q_{l}=i_{v} \alpha_{d}\left(w_{s w}-w_{a}\right) \sigma . d x . d y
\end{aligned}
$$

$\dot{\mathrm{i}}_{\mathrm{v}}$ là enthalpy của hơi ẩm tại bề mặt tiếp giáp có nhiệt độ $\mathrm{t}_{\mathrm{w}}$ của ẩm, $\mathrm{i}_{\mathrm{v}}$ được xác định như sau:

$$
i_{v}=i_{0}+c_{p v} t_{w}
$$

Tổng nhiệt lượng $d Q_{w p}, d Q_{s} v \grave{a} d Q_{l}$ sẽ cân bằng với sự thay đổi nhiệt lượng màng ẩm $d Q_{w}$, nó được thể hiện ở phương trình sau:

$$
d Q_{w}=d Q_{l}+d Q_{s}+d Q_{w p}=i_{v} \alpha_{d}\left(w_{s w}-w_{a}\right) \sigma . d x . d y+d Q_{s}=\alpha_{a}\left(T_{w}-T_{a}\right) \sigma . d x . d y+K_{w}\left(T_{w}-T_{p}\right) \sigma . d x . d y
$$

Phương trình biểu diễn bay hơi khi phun sương như sau:

$$
-\frac{d x}{L_{x}} \frac{\partial m_{w}}{\partial y}=\alpha_{d}\left(w_{s w}-w_{a}\right) \sigma \cdot d x \cdot d y
$$

Biến đổi phương trình (16) sẽ dẫn đến phương trình sau:

$$
\frac{\partial m_{w}}{\partial y}=L_{x} \alpha_{d}\left(w_{a}-w_{s w}\right) \sigma
$$

Toàn bộ nhiệt lượng trao đổi với nhau sẽ làm nội năng thay đổi, dẫn đến phương trình sau: 


$$
\begin{aligned}
& d Q_{w}=c_{w} \frac{d x}{L_{x}}\left(m_{w}+\frac{\partial m_{w}}{\partial y} d y\left(T_{w}+\frac{\partial T_{w}}{\partial y} d y\right)-c_{w} \frac{d x}{L_{x}} m_{w} T_{w}=\right. \\
& =c_{w} \frac{d x}{L_{x}}\left(\frac{\partial m_{w}}{\partial y} d y T_{w}+m_{w} \frac{\partial T_{w}}{\partial y} d y+\frac{\partial m_{w}}{\partial y} d y\right) \cdot \frac{\partial T_{w}}{\partial y} d y
\end{aligned}
$$

Kết hợp với phương trình (15) thì nhận được phương trình sau:

$$
\begin{aligned}
& c_{w} \frac{d x}{L_{x}}\left(\frac{\partial m_{w}}{\partial y} d y T_{w}+m_{w} \frac{\partial T_{w}}{\partial y} d y+\frac{\partial m_{w}}{\partial y} d y\right) \cdot \frac{\partial T_{w}}{\partial y} d y= \\
& =i_{v} \alpha_{d}\left(w_{s w}-w_{a}\right) \sigma, d x . d y+d Q_{s}=\alpha_{a}\left(T_{w}-T_{a}\right) \sigma . d x . d y+K_{w}\left(T_{w}-T_{p}\right) \sigma . d x . d y
\end{aligned}
$$

Mở ngoặc và bỏ qua vy phân bậc 2 vì giá trị của nó rất bé sẽ dẫn đến phương trình sau:

$$
\frac{\partial T_{w}}{\partial y}=\frac{L_{x}}{m_{w} c_{w}}\left[h_{d}\left(w_{a}-w_{s w}\right) \sigma\left(i_{v}-T_{w} c_{p w}\right)+\alpha_{a}\left(T_{a}-T_{w}\right) \sigma+K_{w}\left(T_{p}-T_{w}\right) \sigma\right]
$$

\section{3 Ở dòng thứ cấp}

Độ ẩm không khí ở dòng thứ cấp tăng lên do phun sương đồng thời dòng thứ cấp trao đổi nhiệt hiện với dòng sơ cấp và lớp ẩm. Cân bằng ẩm qua truyền khối giữa lớp ẩm và dòng thứ cấp được biểu thị bởi phương trình sau:

$$
m_{a} \frac{d x}{L_{y}} \frac{\partial w_{a}}{\partial y} d y=\alpha_{d}\left(w_{s w}-w_{a}\right) \sigma . d x . d y
$$

Sau khi biến đổi sẽ dẫn đến phương trình:

$$
\frac{\partial w_{a}}{\partial y}=\frac{L_{x}}{m_{a}} \alpha_{d}\left(w_{s w}-w_{a}\right) \sigma
$$

Sự biến đổi nhiệt ẩn sẽ diễn ra ngay tại bề mặt tiếp xúc giữa không khí và ẩm do chênh lệch nồng độ hơi ẩm. Nhiệt lượng đó là:

$$
d Q_{l}=i_{v} \alpha_{d}\left(w_{s w}-w_{a}\right) \sigma . d x . d y
$$

Nhiệt lượng trao đổi bằng đối lưu giữa lớp ẩm và không khí sẽ là:

$$
d Q_{s}=\alpha_{a}\left(T_{w}-T_{a}\right) \sigma \cdot d x \cdot d y
$$

Toàn bộ nhiệt lượng trao đổi của dòng thứ cấp là $d Q_{l}, d Q_{s}$ và $d Q_{a p}$, từ đó có phương trình sau: $d Q_{l}+d Q_{s}+d Q_{p a}=i_{v} \alpha_{d}\left(w_{s w}-w_{a}\right) \sigma . d x . d y+\alpha_{a}\left(T_{w}-T_{a}\right) \sigma . d x . d y+K_{a}\left(T_{p}-T_{a}\right)(1-\sigma) d x . d y(25)$

Sự trao đổi nhiệt ẩn và nhiệt hiện làm thay đổi enthalpy của dòng thứ cấp, nó được biểu diễn bởi phương trình sau:

$$
d Q_{a}=m_{a} \frac{d x}{L_{x}} \frac{\partial i_{a}}{\partial y} d y
$$

Kết hợp phương trình (25) và (26) sẽ dẫn đến phương trình sau:

$$
\frac{\partial i_{a}}{\partial y}=\frac{L_{x}}{m_{a}}\left[i_{v} \alpha_{d}\left(w_{s w}-w_{a}\right) \sigma+\alpha_{a}\left(T_{w}-T_{a}\right) \sigma+K_{a}\left(T_{p}-T_{a}\right)(1-\sigma)\right]
$$

Trong phương trình (27), $\partial i_{a}$ được xác định như sau:

$$
\partial i_{a}=\left(c_{p a}+w_{a} c_{p v}\right) \partial T_{a}+\left(c_{p v} T_{a}+i_{0}\right) \partial w_{a}
$$

Có thể xác định được rằng:

$$
\frac{\partial T_{a}}{\partial y}=\frac{L_{x} h_{a}}{m_{a} c_{a}}\left[1+\frac{c_{p v}}{c_{p a}} \alpha_{d}\left(w_{s w}-w_{a}\right)\right]\left(T_{w}-T_{a}\right)
$$

Trong đó nhiệt dung riêng của không khí ẩm là: $c_{a}=c_{p a}+w_{a} c_{p v}$. 
Tổng hợp từ các phương trình (9), (20), (22) và (29) theo quy luật bảo toàn khối lượng và bảo toàn năng lượng đôi với hướng chuyển động ngược chiều, giao cắt nhau của các dòng trong IEC, sẽ dẫn đến hệ phương trình sau đây:

$$
\begin{gathered}
\frac{\partial T_{p}}{\partial x}=\frac{L_{y}}{m_{p} c_{p}}\left[K_{w}\left(T_{w}-T_{p}\right) \sigma+K_{a}\left(T_{a}-T_{p}\right)(1-\sigma)\right] \\
\frac{\partial T_{w}}{\partial y}=\frac{L_{x}}{m_{w} c_{w}}\left[\alpha_{d}\left(w_{a}-w_{s v}\right) \sigma\left(i_{v}-T_{w} c_{p w}\right)+\alpha_{a}\left(T_{a}-T_{w}\right) \sigma+K_{w}\left(T_{p}-T_{w}\right) \sigma\right] \\
\frac{\partial w_{a}}{\partial y}=\frac{L_{x}}{m_{a}} h_{d}\left(w_{s v}-w_{q}\right) \sigma \\
\frac{\partial T_{a}}{\partial y}=\frac{L_{x} h_{a}}{m_{a} c_{a}}\left[1+\frac{c_{p v}}{c_{p a}}\left(w_{s v}-w_{a}\right)\right]\left(T_{w}-T_{a}\right)
\end{gathered}
$$

\subsection{Hệ số truyển nhiệt và truyền khối}

Để tính trao đổi nhiệt giữa kênh khô và ướt thì cần phải xác định hệ số truyền nhiệt trong phương trình (9) và (10). Hệ số tỏa nhiệt đối lưu của dòng sơ cấp phụ thuộc vào trạng thái lưu động của dòng. Hệ số này được xác định theo phương trình sau:

$$
\alpha_{p}=\frac{N u_{p} \cdot K_{p}}{d e_{p}}
$$

Hệ số truyền nhiệt của dòng thứ cấp lưu động qua kênh ướt được xác định qua công thức thực nghiệm của Stoitchkov [10] như sau:

$$
\alpha_{a}=36,31\left(\rho v_{a}\right)^{0,68}\left(\frac{L_{y}}{d e_{a}}\right)^{-9,98}
$$

Hệ số truyền nhiệt của ẩm từ màn sương lưu động ổn định theo hướng cắt ngang dòng không khí được xác định theo $[9,10]$ như sau:

$$
N u_{w}=\frac{\alpha_{w} \delta_{w}}{\lambda_{w}}=1,88 ; \quad \delta_{w}=\left(\frac{3 \Gamma \mu_{w}}{g \rho_{w}^{2}}\right)^{1 / 3} ; \quad \Gamma=\frac{m_{w}}{(N+1) L_{x}}
$$

Trong đó $\delta_{\mathrm{w}}$ là bề dày của màn sương, $\mathrm{N}$ là số vách, $\Gamma$ là lượng ẩm tuyến tính, $\mathrm{kg} /(\mathrm{m} . \mathrm{s})$.

Thông thường thì đánh giá chính xác sai lệch của hệ số truyền khối thật sự khó khăn, phức tạp. Nhiều tác giả đã nghiên cứu ảnh hưởng của chỉ số Lewis đến hiệu quả của IEC. Chỉ số Lewis được xác định như sau:

$$
L e_{f}=\frac{S t}{S t_{m}}=\frac{\alpha}{c_{p} \alpha_{d}}=\left(\frac{\mathrm{Pr}}{S c}\right)^{-2 / 3}=L e^{2 / 3}
$$

\subsection{Hiệu quả của nhiệt độ bầu ướt}

Mức độ suy giảm của nhiệt độ bầu ướt có vai trò quyết định đến hiệu suất của IEC. Thông số đầu vào của dòng thứ cấp được xác định từ trạng thái không khí ở phòng làm việc, thông số này khác với thông số đầu vào của dòng sơ cấp. Nhiệt độ bầu ướt của dòng thứ cấp phải thấp hơn nhiệt độ đầu ra của dòng sơ cấp mới duy trì quá trình truyền nhiệt và truyền khối. Sự chênh lệch nhiệt độ giữa dòng sơ cấp và nhiệt độ bầu ướt của dòng thứ cấp là yếu tố quyết định mức độ giảm nhiệt độ không khí. Nhiệt độ thấp nhất lý tưởng mà dòng sơ cấp đạt được là nhiệt độ bầu ướt tại đầu vào của dòng thứ cấp. Hiệu quả của bầu ướt $\varepsilon_{w b}$ là tỷ số giữa sự suy giảm nhiệt độ thực tế của dòng sơ cấp và nhiệt độ lý tưởng có thể đạt được. Theo [7], hiệu quả của nhiệt độ bầu ướt được xác định như sau: 


$$
\varepsilon_{w b}=\frac{T_{p i}-T_{p o}}{T_{p i}-T_{a i, w b}}
$$

\section{TRÌNH TỰ VÀ KÉT QUẢ MÔ PHỎNG}

Các phương trình (9), (20), (22) và (29) được sử dụng trong quá trình tính toán truyền nhiệt và truyền khối trong IEC. Có thể có 4 phương án chuyển động các dòng, ở đây chúng tôi chỉ giới thiệu phương án tính toán với phương thức lưu động của dòng được ứng dụng rộng rãi. Đó là dòng sơ cấp chuyển động ngược chiều với dòng thứ cấp và màn sương phun ẩm lưu động giao cắt dòng sơ và thứ cấp. Sơ đồ lưu động của các dòng được minh họa trên hình 6 .

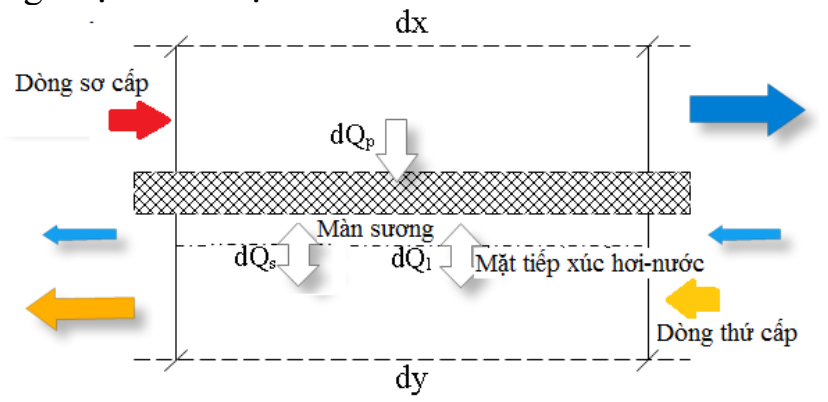

Hình 6. Sơ đồ lưu động của các dòng trong IEC

Để giải các phương trình trên cần phải kèm theo các điều kiện sau đây.

\section{1. Điều kiện ban đầu và điều kiện biên}

Dòng ẩm của phun sương lưu động tuần hoàn từ bình chứa đến vòi phun nên nhiệt độ nước vào và ra không thay đổi, vì vậy phương trình biểu diễn dòng nhiệt của nó là:

$$
\int_{0}^{L x} \int_{0}^{L y} d Q_{W}=0
$$

Đối với dòng sơ cấp:

$$
\int_{0}^{L x} \int_{0}^{L y} d Q_{W}=0, T_{p}(x=0)=T_{p i}
$$

Đối với dòng thứ cấp:

$$
T_{a}(\mathrm{y}=0)=T_{a i}, w_{a}(\mathrm{y}=0)=w_{a i}
$$

\subsection{Trình tự mô phỏng}

Các phương trình (9), (20), (22), (29) cùng điều kiện biên hình thành tổ hợp thích ứng với ứng dụng MATLAB để mô phỏng trên máy tính cho phun ẩm gián tiếp với dòng ngược chiều và giao cắt nhau. Trước khi mô phỏng, cần phải nhập dữ liệu cơ bản và trạng thái không khí ban đầu, vận tốc tối thiểu của dòng khí ở vùng giao nhau $\mathrm{v}_{\mathrm{p}}, \mathrm{v}_{\mathrm{a}}$ và nhiệt độ không khí $\mathrm{t}_{\mathrm{p}}$, $\mathrm{t}_{\mathrm{ai}}$. Các dữ liệu này là cơ sở của miền tính toán. Dựa trên những dữ liệu này, máy tính sẽ thực hiện tính toán toàn diện để xác định hệ số truyền nhiệt và hệ số truyền khối tương ứng. Miền tính toán sẽ được chia thành nhiều phân đoạn tương ứng với từng phương trình chi phối. Mỗi phương trình chi phối chứa các phần tử vô cùng bé và sẽ tính cho từng phần tử. Kết quả cho phần tử trước được coi là dữ liệu đầu vào cho phần tử tiếp theo. Quá trình mô phỏng sẽ hoàn thành cho đến khi điều kiện biên cho nước tuần hoàn, theo phương trình (35) được thỏa mãn. Quá trình tính toán được minh họa ở hình 7 . Trong quy trình mô phỏng này, quá trình tính lặp để xác định nhiệt độ của nước tuần hoàn là quan trọng nhất vì không biết được nhiệt độ này ngay từ đầu. 


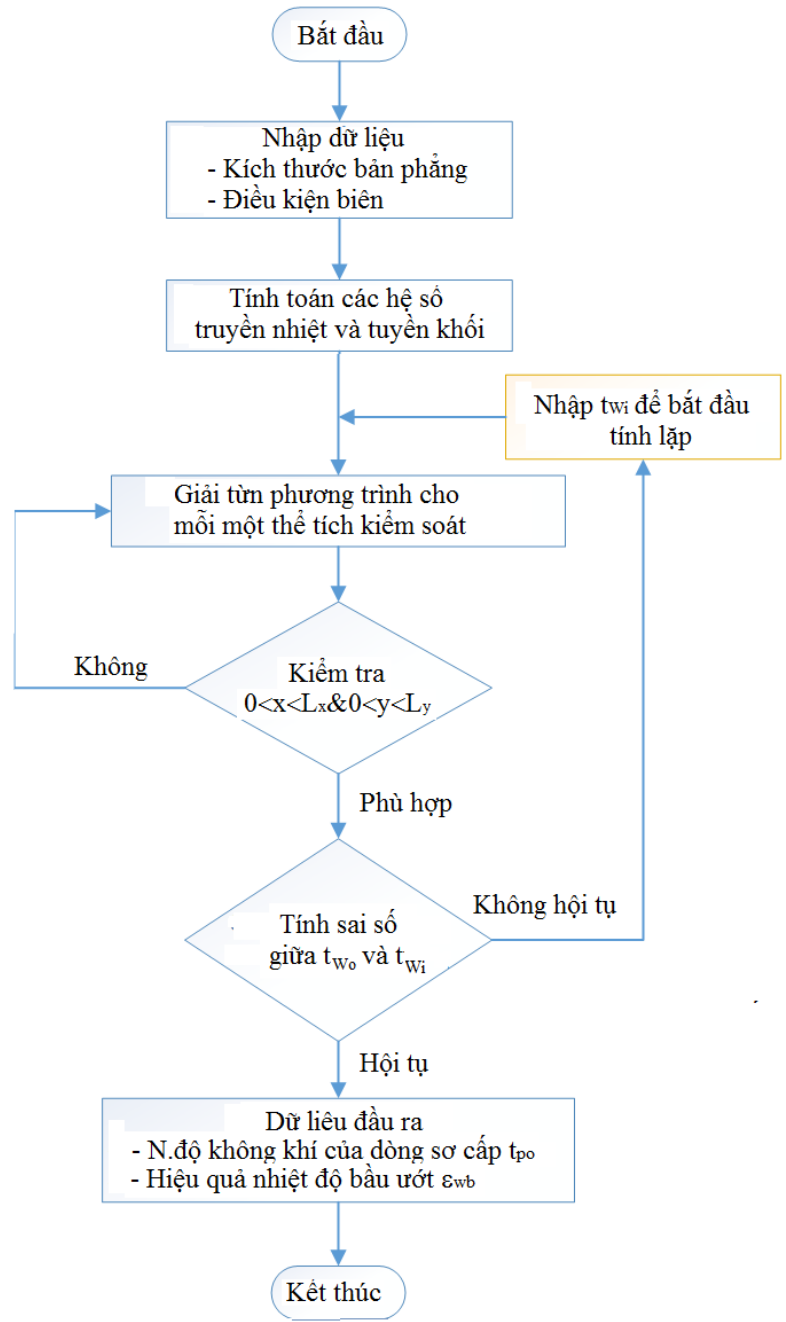

Hình 7. Biểu đồ biểu diễn quá trình mô phỏng

Kết quả mô phỏng với lưu lượng không khí khác nhau được biểu diễn trên hình $8 \mathrm{a}, 8 \mathrm{~b}$ và $8 \mathrm{c}$.

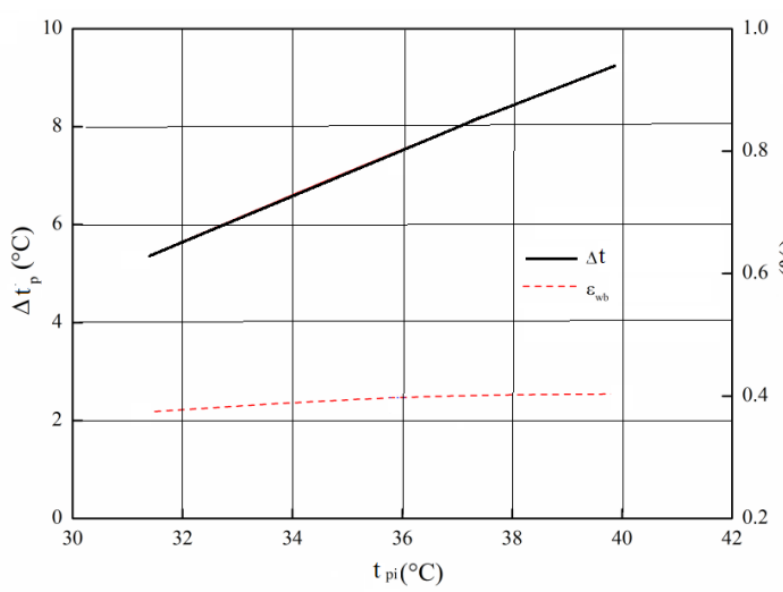

Hình $8 \mathrm{a}$. Kết quả mô phỏng với lưu lượng dòng sơ cấp $200 \mathrm{~m}^{3} / \mathrm{h}$

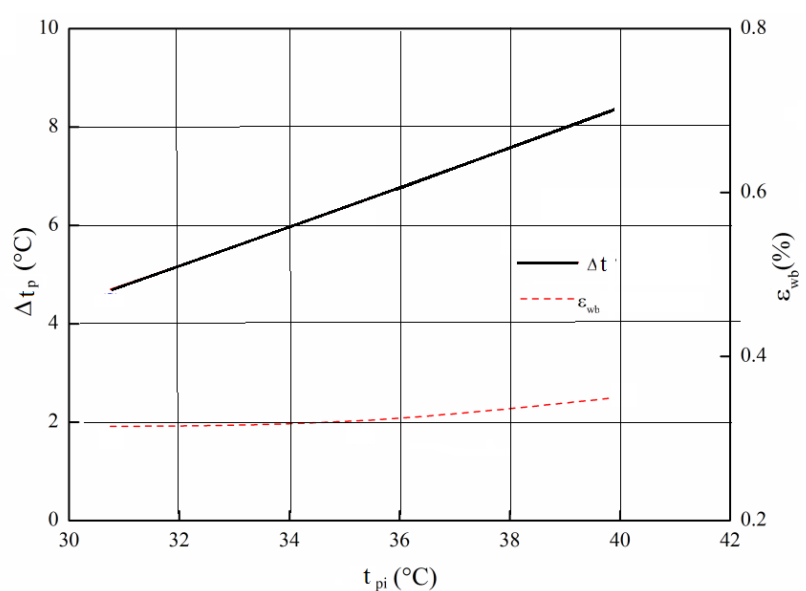

Hình 8b. Kết quả mô phỏng với lưu lượng dòng sơ cấp là $300 \mathrm{~m}^{3} / \mathrm{h}$ 


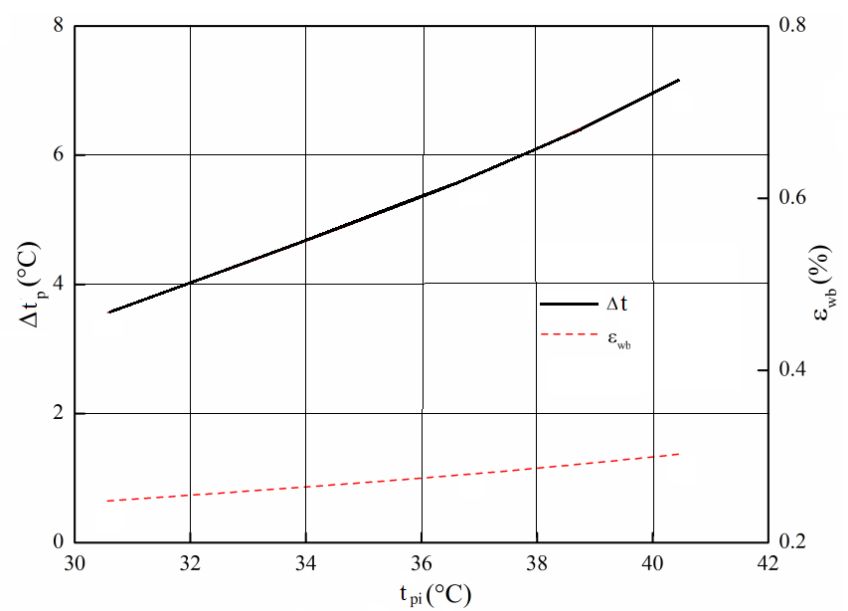

Hình $8 \mathrm{c}$. Kết quả mô phỏng với lưu lượng dòng sơ cấp là $400 \mathrm{~m}^{3} / \mathrm{h}$

\section{KẾT LUẬN}

Bài báo này trình bày nghiên cứu tương đối toàn diện mô hình thiết bị điều hòa không khí qua phun ẩm với dòng không khí lưu động ngược chiều và dòng phun ẩm giao cắt hai dòng không khí đó và mô phỏng quá trình truyền nhiệt và chuyển khối xảy ra bên trong thiết bị đó. Mô hình tính toán trên hệ tọa độ hai chiều kết hợp sự biến thiên nhiệt độ màng ẩm ở phần bề mặt vách ẩm ướt trong quá trình lưu động và sử dụng yếu tố Lewis để nâng cao độ chính xác của mô hình và khả năng làm cho nó gần gũi hơn với tình hình thực tế.

Để kiểm định mức độ tin cậy cho quá trình tính toán này cần phải chế tạo mô hình để so sánh số liệu đo đạc trên mô hình thực với kết quả tính toán. Thí nghiệm đầu tiên là có thể lập mô hình thí nghiệm để so sánh kết quả của tác giả [10], ở đó bộ trao đổi nhiệt dạng hình khối, tiết diện của kênh khô và ướt có đường kính tương đương $7 \mathrm{~mm}$. Dữ liệu xác nhận thứ hai bắt nguồn từ các thí nghiệm được thực hiện bởi Gomez [12], người đã nghiên cứu về hiệu suất nhiệt của thiết bị trao đổi nhiệt, có kích thước $0,62 \mathrm{~m} x$ $0,23 \mathrm{~m} \times 0,18 \mathrm{~m}$ tạo nên bề mặt trao đổi nhiệt là $6 \mathrm{~m}^{2}$, dòng không khí sơ cấp cắt ngang bề mặt ướt. Chúng tôi đang tìm nguồn kinh phí để thực hiện đề tài này.

Ý nghĩa khoa học chủ yếu ở bài báo này không phải là phun ẩm trực tiếp vào không khí để hạ nhiệt độ của chúng mà là mô phỏng một dạng thiết bị trao đổi nhiệt có hướng chuyển động của các dòng đối lưu khác nhau, cách bố trí bề mặt trao đổi nhiệt cũng như sắp xếp chất hút ẩm để giảm độ ẩm không khí, từ đó định hướng cho thiết kế mô hình thí nghiệm. Qua thí nghiệm có thể xây dựng đường đặc tính của thiết bị rồi mở rộng ứng dụng để điều hòa không khí cho những vùng nóng, ẩm, có độ ẩm không khí cao như ở Việt Nam, khi đó phun ẩm trực tiếp không có tác dụng nhiều vì không khí dễ bão hòa khi phun ẩm trực tiếp.

\section{TÀI LIỆU THAM KHẢO}

[1] Amer, O., Boukhanouf, R., \& Ibrahim, H. G., A Review of Evaporative Cooling Technologies. International Journal of Environmental Science and Development, 6(2) (2015) pp111.

[2] Y. J. Dai and K. Sumathy, "Theoretical study on a cross-flow direct evaporative cooler using honeycomb paper as packing material," Applied Thermal Engineering, vol. 22, pp. 1417-1430, 9// 2002.

[3] Y. Fan, L. Luo, B. Souyri - Review of solar sorption refrigeration technologies: Development and applications, Renewable and Sustainable Energy Reviews 11 (2007).

[4] Hubert Sturies, Jens Panenberg, Verdunstungskühlung auch für Gebäude, CCI 5/2006. 
[5] Anisimov S., Pandelidis D., Maisotsenko V., Numerical analysis of heat and mass transfer processes through the maisotsenko cycle, 10th International Conference on Heat Transfer, Fluid Mechanics and Thermodynamics, Orlando, Florida, 14 - 26 July (2014).

[6] Hans Dieter Baehr, Karl Stephan - Waerme- und Stoffuebertragung, Springer Heidelberg Dordrecht London New York, (2011).

[7] P. Erens and A. Dreyer, "Modelling of indirect evaporative air coolers," International journal of heat and mass transfer, vol. 36, pp. 17-26, 1993.

[8] N. Stoitchkov and G. Dimitrov, "Effectiveness of crossflow plate heat exchanger for indirect evaporative cooling: Efficacité des échangeurs thermiques à plaques, à courants croises pour refroidissement indirect évaporatif," International journal of refrigeration, vol. 21, pp. 463-471, 1998.

[9] A. Handbook, "HVAC systems and equipment," American Society of Heating, Refrigerating, and Air Conditioning Engineers, 2014.

[10] Constanze Bongs, Experimentelle und mathematisch-numerische Untersuchung von verdunstungsgekühlten, sorptiv beschichteten Wärmeübertragern für die Luftentfeuchtung und -kühlung, Dissertation in der Technischen Universität Berlin, Februar 2013.

[11] Hamid Montazeri, Computational modelling of evaporative cooling as a climate change adaptation measure at the spatial scale of buildings and streets, Dissertation in der Eindhoven University of Technology, May 2015.

[12] A. Tejero-González, M. Andrés-Chicote, E. Velasco-Gómez, and F. J. Rey-Martínez, "Influence of constructive parameters on the performance of two indirect evaporative cooler prototypes", Applied Thermal Engineering, vol. 51, pp. 1017-1025, 2013.

[13] Zhiyin Duan, Investigation of a Novel Dew Point Indirect Evaporative Air Conditioning System for Buildings, Dissertation in the University of Nottingham, September 2011.

Ngày nhận bài: 28/02/2017 Ngày chấp nhận đăng: 08/08/2017 